\title{
Tit for Tat: sticklebacks (Gasterosteus aculeatus) "trusting" a cooperating partner
}

Individual three-spined sticklebacks (Gasterosteus aculeatus) moved closer to a predatory trout when a "cooperator" stickleback, which the test fish could see through a one-way mirror, swam up to the predator than when a "defector" stickleback appeared to swim only half as close to the predator. After four training runs with both types of partners, the former cooperator. also defected. The test fish continued to move closer to the predator in the presence of the former cooperator even though both the former cooperator and the defector now appeared to stop in their approach to the predator at the same distance. This shows that probable partners build up trust. [Behav Ecol 1990;1:7-11]

$\mathrm{W}$ hen a pike (Esox lucius) is stalking a shoal of minnows (Phoxinus phoxi$n u s)$, individual minnows leave the shoal and approach to within four to six body lengths from the predator, wait there for a few seconds, and then slowly turn and go back to the shoal (Magurran et al., 1985; Magurran, Pitcher, 1987; Pitcher et al., 1986). It has been shown that the fish gather information about the predator's identity, precise location, and current motivational state during such inspection visits (Licht, 1989; Magurran, Girling, 1986; Magurran, Higham, 1988). Two minnows, or sticklebacks (Gasterosteus aculeatus), will approach a predator more closely than will single fish (Milinski, 1985; Pitcher et al., 1986). Two inspectors gain similar information but have only half the risk of being eaten per individual compared to singletons. Although the two fish provide each other with the shoal advantage (Hamilton, 1971), the fish that initiates the next step forward has to rely on the other one following. The two fish are probably in a "prisoner's dilemma," a "game" in which defection rather than cooperation is the evolutionarily stable strategy (Milinski, 1987, 1990). This only applies if the game is played either once or a predictable number of times. In such a scenario, mutual cooperation would yield the highest benefit for both individuals (Axelrod, Hamilton, 1981; May, 1981; Maynard Smith, 1982; Trivers, 1971).

A solution to the problem posed by the prisoner's dilemma is provided by the cooperation strategy of Tit for Tat; that is, cooperating in the first game and thereafter doing what your partner did in the preced- ing game. This strategy has been shown to be very successful if the players have a certain minimum probability of meeting again in the same situation (Axelrod, 1984; Axelrod, Dion, 1988; Axelrod, Hamilton, 1981; Boyd, 1989; Feldman, Thomas, 1987; Nowak, Sigmund, 1989; Peck, Feldman, 1986). Although reciprocity has been demonstrated in a number of species (Dugatkin, 1988; Fischer, 1980; Ligon, Ligon, 1978; Lombardo, 1985; Milinski, 1987; Packer, 1977; Seyfarth, Cheney, 1984; Whitehead, 1987; Wilkinson, 1984), only a few investigations have demonstrated experimentally that a number of the conditions and predictions of Tit for Tat are fulfilled (Dugatkin, 1988; Lombardo, 1985; Milinski, 1987, 1990; Whitehead, 1987; Wilkinson, 1984).

Milinski (1987) used a system of mirrors so that single sticklebacks approaching a live predator were provided with either a simulated cooperating companion or a simulated defecting one. In both cases the test fish behaved according to Tit for Tat. By repeating the mirror experiments with guppies (Poecilia reticulata), Dugatkin (1988) found almost the same results. Individual sticklebacks in a group of four have their preferred partner with whom they repeatedly perform inspection visits (Milinski et al., in press). May (1987) has suggested that early encounters could be used to build up trust between partners, so that eventually they may undertake an enterprise with a large reward. In the present study we investigate whether single sticklebacks prefer to join the more cooperative of two possible partners and whether they are willing to "pay
Manfred Milinski David Külling Rolf Kettler Abteilung

Verhaltensökologie, Zoologisches Institut, Universität Bern, Wohlenstrasse 50 a, CH-3032 Hinterkappelen, Switzerland

Address reprint requests to M. Milinski

Received 29 September 1989 Accepted 9 January 1990 1045-2249/90/\$2.00 (4) 1990 International Society for Behavioral Ecology 
Figure 1

Experimental set-up as viewed from above. Outer compartments contain conditioned sticklebacks; experimental compartments in middle contains test fish and plants; predator compartment at right contains a rainbow trout.

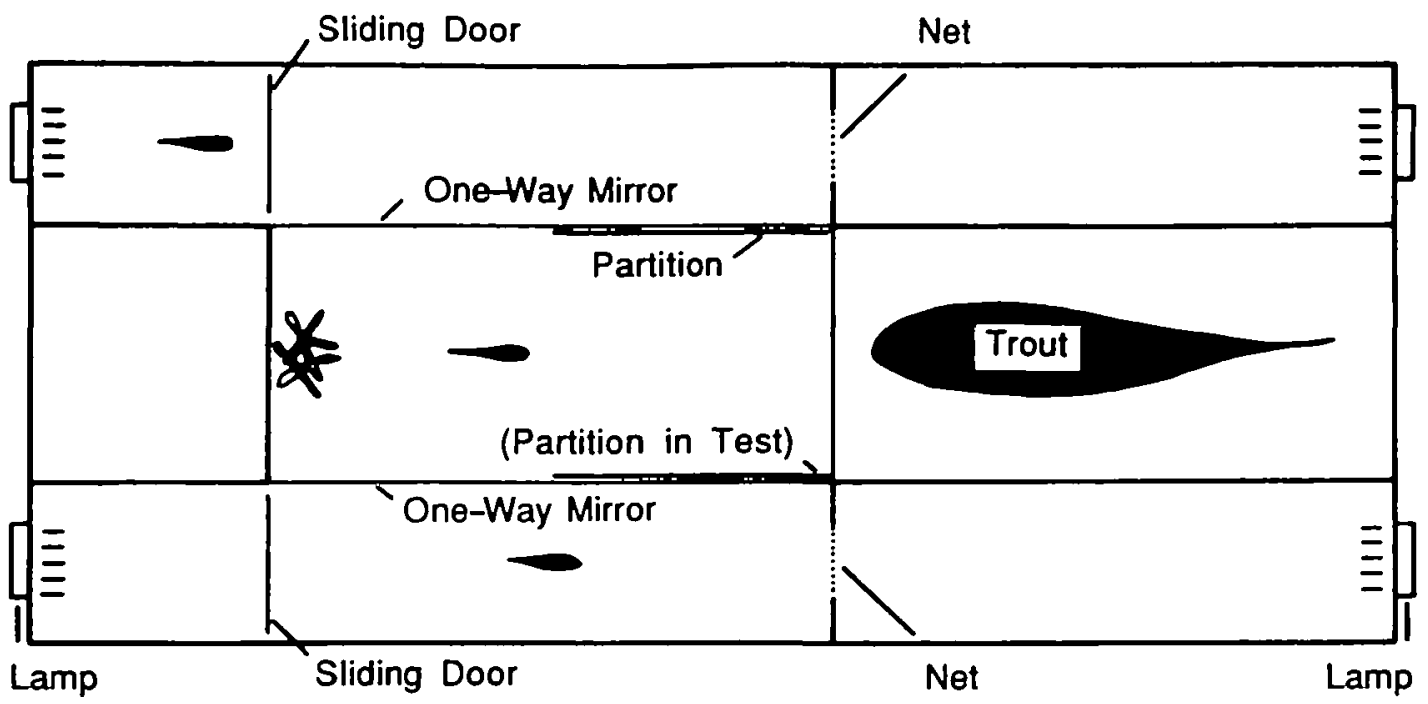

in advance" - that is, approach the predator more closely-when the more cooperative partner is following.

\section{Materials and methods}

We divided the experimental tank $(80 \times 35$ $\mathrm{cm}$ ) into four compartments: an experimental compartment $(33 \times 14.5 \mathrm{~cm})$ containing two plants (Vallisneria sp.) at one end; a predator compartment $(33 \times 14.5 \mathrm{~cm})$ containing a rainbow trout (Oncorhynchus mykiss, about $28 \mathrm{~cm}$ long); and two outer compartments $(80 \times 9 \mathrm{~cm})$, one on either side of the experimental and predator compartments (Figure 1). Each of the outer compartments had a start section at one end from which a conditioned stickleback could be made to swim toward the other end by opening a sliding door and switching on a weak green light positioned at the far end, outside the backwall. When a conditioned stickleback came within $5 \mathrm{~cm}$ of a net positioned at the same distance as the glass partition between the experimental and predator compartments, we switched off the green light and switched on another green light positioned at the starting end. This made the conditioned fish swim back to the start section, where it was then trapped behind the sliding door. We used two different female sticklebacks that we had individually conditioned to swim toward green lights by rewarding this behavior after a variable ratio schedule with Tubifex worms under closed-economy conditions for several weeks. We had fed the trout sticklebacks.

Both long walls of the experimental compartment consisted of one-way mirrors. We illuminated each of the two outer compartments from above using two white lamps (Osram Concentra PAR-EC flood, $80 \mathrm{~W}$ ) suspended $78 \mathrm{~cm}$ above the water level (18 $\mathrm{cm})$. The experimental and predator compartments were illuminated only by the light passing through the mirrors. Thus, a conditioned fish could be seen from the experimental compartment, into which the conditioned fish, however, could not see. We set up a video camera above the experimental tank to film the experimental and predator compartments.

Before the start of each trial, we kept the two conditioned sticklebacks in their individual start sections and released a test stickleback above the plants in the experimental compartment. We positioned an opaque partition in front of the predator compartment and another in front of a one-way mirror covering the half $(16.5 \mathrm{~cm})$ of the experimental compartment closest to the predator. The test fish was given $30 \mathrm{~min}$ to become accustomed to the tank. At the start of each trial, we placed the trout in the predator compartment and raised the opaque partition in front of it. Then we sent one of the two conditioned sticklebacks forward and back again in the outer compartment before trapping it in its start section. Then the second conditioned fish was made to swim in the same way. We sent the two conditioned fish alternately forward and back four times each (this was the training of the test fish). We alternated the sequence of the conditioned fish and the position of the opaque partition from side to side between different test fish so that each possible combination was met almost equally often. After eight training runs, we placed a second partition in the equivalent position to the first, that is, in front of the opposite one-way mirror in the half closest to the predator (Figure 1). As before, we sent each conditioned fish alternately forward and back four times (this 
constituted the testing phase). We used each of 48 test fish only once.

As well as video recording the behavior of both the test fish and the predator, we observed the course of each conditioned fish directly from behind a blind. We divided the part of the outer compartments between sliding door and net into six sequentially numbered sections of equal length. We used these numbered sections to record the position of the conditioned fish. The shortest distance between the test fish and the glass partition next to the predator was measured during each run of a conditioned fish both when the conditioned fish was in the half of the outer compartment closer to the predator and when it was in the other half on its way back to the start section.

\section{Results}

In the majority of the eight training runs, the test fish approached the predator in synchrony with a conditioned fish. Because of the opaque partition that was positioned on one side of the experimental compartment, the test fish was able to see one of the conditioned fish (the "defector") swimming about half the available distance toward the predator and the other fish (the "cooperator") swimming until it was close to the trout. The trout tried to attack each test fish several times between the start of a trial and the last test run, especially when the test fish was close to the trout.

During each of the training runs, the test fish came closer to the predator with the cooperator than with the defector (Figure 2). The difference between the means of all four training runs combined with either companion was significant $(p<.02$, onetailed Wilcoxon matched-pairs signed-ranks test). In all eight test runs both of the conditioned fish were seen to approach only halfway to the predator. In the second and third test runs, the test fish tended to move closer to the predator with the conditioned fish that had cooperated during the training runs (Figure 2). When the second partition was placed in front of the cooperator's side immediately before the first test run, the test fish appeared frightened by this disturbance. This is supported by the fact that 25 test fish which started with the cooperator in the first test run tended to approach the predator more closely with the former defector whereas the 23 test fish that started with the defector tended to swim more closely to the predator with the former cooperator ( $\phi<.05$, one-tailed $U$ test). Therefore, the disturbance had a conservative effect with respect to the hypothesis and was

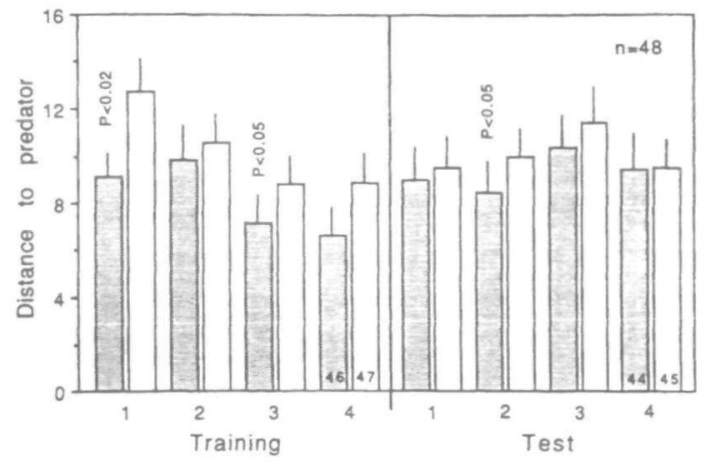

most pronounced in the test run that immediately followed the disturbance.

When the conditioned fish was in the half of its compartment close to its start section on its way back, the test fish also returned from its inspection visit. This is depicted by the test fish's greater distance to the predator (Figure 3) as compared to when the conditioned fish was close to the predator (Figure 2). However, the test fish returned more slowly when it had started the inspection visit with the cooperator than with the defector. During each of the training runs, the test fish was significantly closer to the predator with the cooperator than with the defector (Figure 3). This was also the case in each of the first two test runs. Thereafter, the test fish reacted to the cooperator and to the defector in the same way.

\section{Discussion}

Although we are using words such as "trust," we do not assume that our fish were consciously trusting. What looked like trust may have been simply the result of applying a rule that generates behavior which has been described as "nice, retaliating and forgiving" (Axelrod, 1984).

In the four training runs with either the cooperator or the defector, the test sticklebacks moved closer to the predator when they were accompanied by the cooperating partner. Because neither the cooperator nor

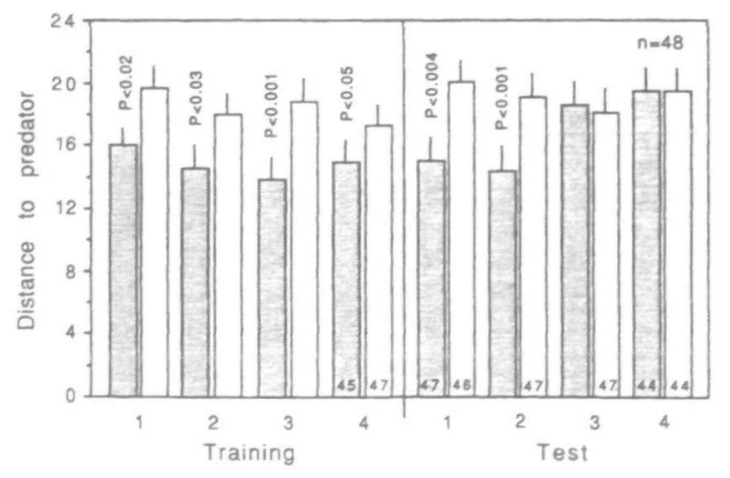

Figure 2

Average $( \pm S E)$ minimum distance $(\mathrm{cm})$ between the test fish and the predator when the conditioned fish was in the half of its compartment closer to the predator during training runs and test runs. Shaded columns show runs with the cooperator, unshaded columns show runs with the defector; $n$ = number of trials with different test fish, $n$ with missing values shown in columns; $p=$ significant $(<.05)$ differences between runs with cooperator and defector after one-tailed Wilcoxon matched-pairs signed-ranks test.

\section{Figure 3}

Average ( $\pm S E$ ) minimum distance $(\mathrm{cm})$ between the test fish and the predator when the conditioned fish was in the half of its compartment close to its start section on its return during training runs and test runs. Other explanations as in Figure 2. 
the defector could see the test fish, it must have been the test fish's decision to move closer to the predator with the cooperator. In both cases the test fish simply could have followed the other fish. No cooperation needs to be involved here, in contrast to previous mirror experiments (Milinski, 1987) in which the cooperating mirror image proceeded only when the test fish moved forward. In the test runs, however, the test fish saw both the former cooperator and the defector approaching the predator up to the defector's distance. The test fish moved closer to the predator after the former cooperator had disappeared behind a partition (i.e., defected), as had the defector. As both the cooperator and the defector defected in the test runs at exactly the same distance from the predator, the test fish's closer approach to the predator can be interpreted as "paying for trust." When a partner appeared that had previously cooperated, the test stickleback was willing to take the next step toward the predator, which is equivalent to "cooperate for cooperate" in the Tit for Tat strategy.

Because the roles of defector and cooperator were alternated between the two conditioned fish from test fish to test fish, the experimental results were caused neither by individual differences between the two conditioned fish nor by a hidden asymmetry of the tank. Although we cannot rule out that each test fish learned on which side it could expect its cooperator to appear, we have evidence for individual recognition of the cooperating partner from another study (Milinski et al., in press).

The finding that the test fish continued to cooperate with the former cooperator until after this fish had defected twice suggests that the sticklebacks were playing $T$ it for Two Tats, a strategy that has been shown to be more successful sometimes than Tit for Tat (Axelrod, 1984; Boyd, Lorberbaum, 1987). However, it is possible that the number of defections, which are accepted before a defection is the answer, is a function of the amount of "trust" that has been built up. Possibly we would have found something such as Tit for Four Tats after 10 training runs with the cooperator. Furthermore, it is possible that the fish use strategies with some realistic stochasticity in them (May, 1987), such as cooperation with a probability of $90 \%$ after the partner has defected once, with a probability of $80 \%$ after its second defection, and so on.

In a companion study (Milinski et al., in press), it has been shown that sticklebacks in groups of four have preferred partners with whom they cooperate repeatedly. The present study suggests the mechanism by which such reciprocal pairs may build up trust. This is to make the next cooperative step when the partners that follow are those that had been seen to "pay in advance" themselves. This study and previous ones (Milinski, 1987, 1990; Milinski et al., in press) have shown that the sticklebacks' behavior is compatible with a cooperation strategy modeled on Tit for Tat. This does not mean that a different cooperation strategy could not explain the results better. There is clearly a need for alternative strategies against which Tit for Tat can be tested.

We thank Theo Bakker, Alex Kacelnik, and Anne Magurran for comments, and Olivia Lassiere for improving our English.

\section{References}

Axelrod R, 1984. The evolution of cooperation. New York: Basic Books.

Axelrod R, Dion D, 1988. The further evolution of cooperation. Science 242:1385-1390.

Axelrod R, Hamilton WD, 1981. The evolution of cooperation. Science 211:1390-1396.

Boyd $R, 1989$. Mistakes allow evolutionary stability in the repeated prisoner's dilemma game. J Theor Biol 136:47-56.

Boyd R, Lorberbaum JP, 1987. No pure strategy is evolutionarily stable in the repeated prisoner's dilemma game. Nature 327:58-59.

Dugatkin LA, 1988. Do guppies play Tit for Tat during predator inspection visits? Behav Ecol Sociobiol 23: 395-399.

Feldman MW, Thomas EAC, 1987. Behavior-dependent contexts for repeated plays of the prisoner's dilemma II: dynamical aspects of the evolution of cooperation. J Theor Biol 128:297-315.

Fischer EA, 1980. The relationship between mating system and simultaneous hermaphroditism in the coral reef fish, Hypoplectrus nigricans (Serranidae). Anim Behav 28:620-633.

Hamilton WD, 1971. Geometry for the selfish herd. J Theor Biol 31:295-311.

Licht T, 1989. Discriminating between hungry and satiated predators: the response of guppies (Poecilia reticulata) from high and low predation sites. Ethology 82:238-243.

Ligon JD, Ligon SH, 1978. Communal breeding in the green woodhoopoe as a case for reciprocity. Nature 176:496-498.

Lombardo MP, 1985. Mutual restraint in tree swallows: a test of the Tit for Tat model of reciprocity. Science 227:1363-1365.

Magurran AE, Girling, SL, 1986. Predator model recognition and response habituation in shoaling minnows. Anim Behav 34:510-518.

Magurran AE, Higham A, 1988. Information transfer across fish shoals under predator threat. Ethology 78:153-158.

Magurran AE, Oulton WJ, Pitcher TJ, 1985. Vigilant behaviour and shoal size in minnows. Z Tierpsychol 67:167-178.

Magurran AE, Pitcher TJ, 1987. Provenance, shoal size and the sociobiology of predator-evasion behaviour in minnow shoals. Proc R Soc Lond B 229:439-465.

May RM, 1981. The evolution of cooperation. Nature 292:291-292. 
May RM, 1987. More evolution of cooperation. Nature 327:15-17.

Maynard Smith J, 1982. Evolution and the theory of games. Cambridge: Cambridge University Press.

Milinski M, 1985, Risk of predation of parasitized sticklebacks (Gasterasteus aculeatus L.) under competition for food. Behaviour 93:203-216.

Milinski $\mathrm{M}, 1987$. Tit for Tat in sticklebacks and the evolution of cooperation. Nature 325:433-435.

Milinski M, 1990. No alternative to Tit for Tat cooperation in sticklebacks. Anim Behav 39:989-991.

Milinski $M$, Pfluger $D$, Külling $D$, Kettler $R$, in press. Do sticklebacks cooperate repeatedly in reciprocal pairs? Behav Ecol Sociobiol.

Nowak M, Sigmund K, 1989. Oscillations in the evolution of reciprocity. J Theor Biol 137:21-26.

Packer C, 1977. Reciprocal altruism in Papio anubus. Nature 265:441-443.

Peck JR, Feldman MW, 1986. The evolution of helping behavior in large randomly-mixed populations. Am Nat 127:209-221.

Pitcher TJ, Green DA, Magurran AE, 1986. Dicing with death: predator inspection behaviour in minnow shoals. J Fish Biol 28:438-448.

Seyfarth RM, Cheney DL, 1984. Grooming, alliances and reciprocal altruism in vervet monkeys. Nature 308:541-543.

Trivers RL, 1971. The evolution of reciprocal altruism. Q Rev Biol 46:35-57.

Whitehead JM, 1987. Vocally mediated reciprocity between neighbouring groups of mantled howling monkeys, Alouatta palliata palliata. Anim Behav 35:16151627.

Wilkinson GS, 1984. Reciprocal food sharing in the vampire bat. Nature 908:181-184. 